ABCDDV/1066

ABCD Arq Bras Cir Dig

Letter to the Editor

2014;27(3):80-83

\title{
ENDOSCOPIC TREATMENT OF POST VERTICAL GASTRECTOMY FISTULA: SEPTOTOMY ASSOCIATED WITH AIR EXPANSION OF INCISURA ANGULARIS
}

Tratamento endoscópico de fístulas pós-gastrectomia vertical: septotomia associada à dilatação pneumática da incisura angular

\section{João Henrique Felício de LIMA}

From the Serviço de Endoscopia Digestiva e Bariátrica - EndoBatel, Hospital Vita Batel (Digestive and Bariatric Endoscopy Service, Vita Batel Hospital), Curitiba, PR, Brazil

Financial source: none Conflicts of interest: none

\section{Correspondence:}

João Henrique Felício de Lima jhflima@terra.com.br
Received for publication: 12/03/2013 Accepted for publication:24/07/2014

\section{INTRODUCTION}

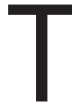
eatment of gastric leaks met new challenges with sleeve gastrectomy, as exclusive bariatric surgery ${ }^{1}$. Mistakenly seen as simpler, many inexperienced surgeons in laparoscopic and bariatric surgery began its use in patients. Was recognized that these fistulas are difficult to treat requiring multiple endoscopic treatments, reoperation and gastric resection ${ }^{2,3,4}$. Using the same principle of septotomies performed in gastric bypass complications, this pioneering author used this method for cases of fistula of the esophagogastric angle and gastric body after vertical gastrectomy.

\section{CASE REPORT}

Woman 54 year old with grade III obesity (BMI $=43.2$ $\mathrm{kg} / \mathrm{m}^{2}$ ) associated with hypertension and severe arthropathy of the right knee underwent laparoscopic sleeve gastrectomy without complications and oversuture on staple line. Evolved with systemic signs of fistula (tachycardia, tachypnea, fever and foul smelling acid secretion in the drain) on the $9^{\text {th }}$ day postoperatively. Was treated in the service of origin with antibiotics and nutrition via a nasogastric tube. Endoscopy observed fistulous orifice of $10 \mathrm{~mm}$ in the topography of the esophagogastric angle. Computed tomography showed perigastric cavity, but with no intra-abdominal abscesses. Contrasted radiography study demonstrated extravasation on angle site (Figure 1); clinically it was, on daily basis by Penrose drain number 2, of $30-50 \mathrm{ml}$. She was referred for endoscopic treatment on day 30 after surgery which revealed a fistulous hole $10-12 \mathrm{~mm}$ in esophagogastric angle and stenosis with excessive angulation of the incisura angularis (Figure 2).

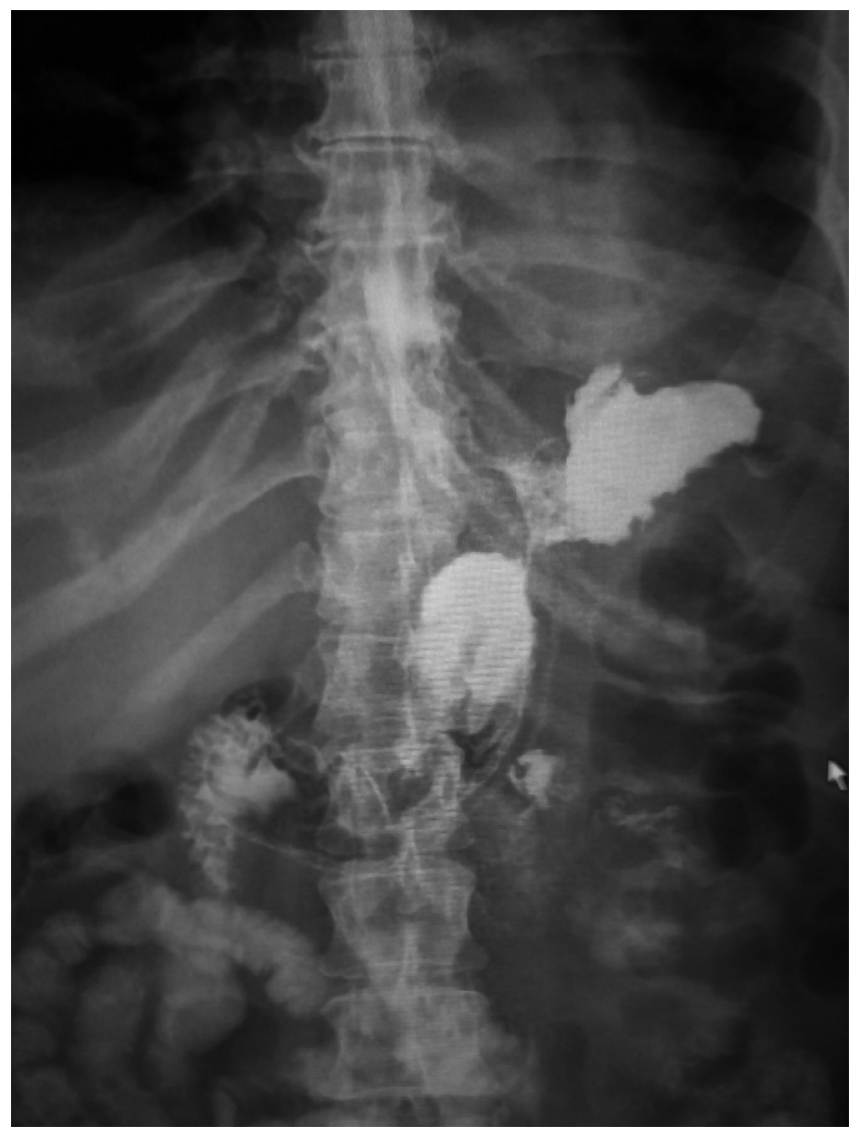

FIGURE 1 - Radiography showing contrast extravasation forming an lateral extra-gastric cavity at the site of the esophagogastric angle

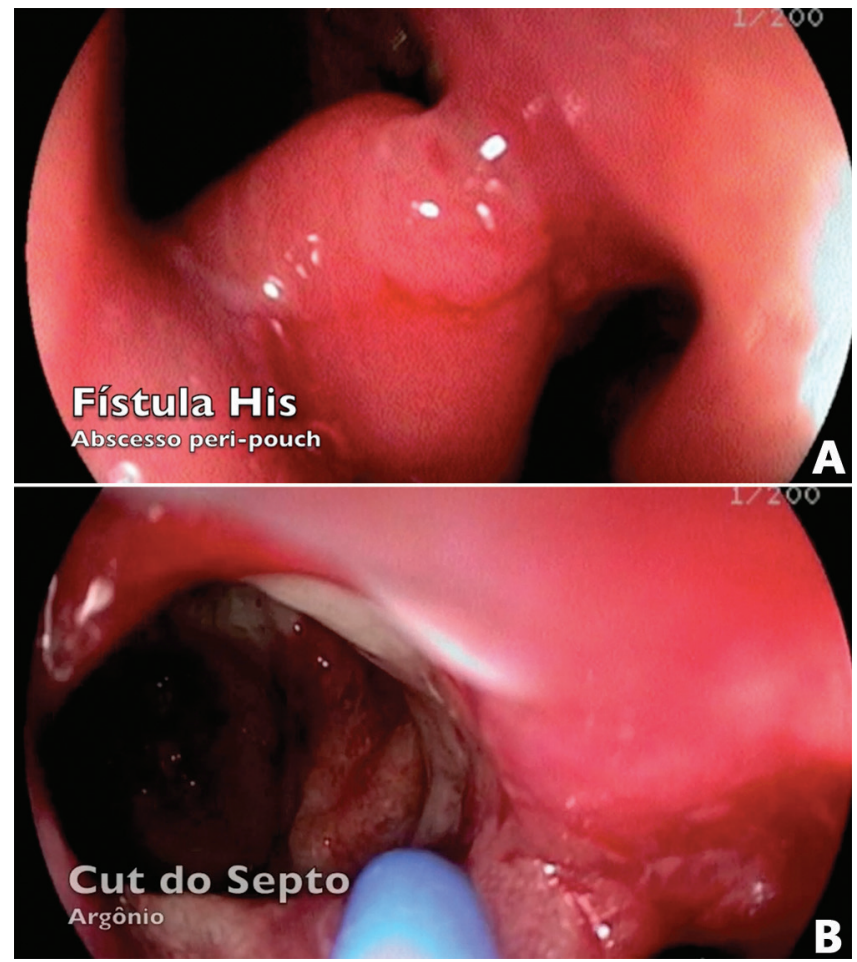

FIGURE 2 - Endoscopic septotomy procedure: A) endoscopic appearance of the fistula at the esophagogastric angle; B) septotomy being held

During the endoscopic procedure performed in the operating room with patient with respiratory intubation, the first step was to expand the incisure with Rigiflex type balloon $40 \mathrm{~mm}$ in high pressure. Later there was the opening of the 
mucous septum between peri-gastric pouch abscess cavity and the body lumen in itself (septotomy or septoplasty or "internal endoscopic drainage"). It was performed with argon catheter $2 \mathrm{l} / \mathrm{m}$ and $90 \mathrm{w}$, in order to avoid bleeding in this inflamed and hypervascularized area (Figure 3). The drain that communicated the peri-bag cavity skin was removed in the same procedure, due it was considered epithelized the fistula interior by time evolution. A liquid diet was started in $24 \mathrm{~h}$.

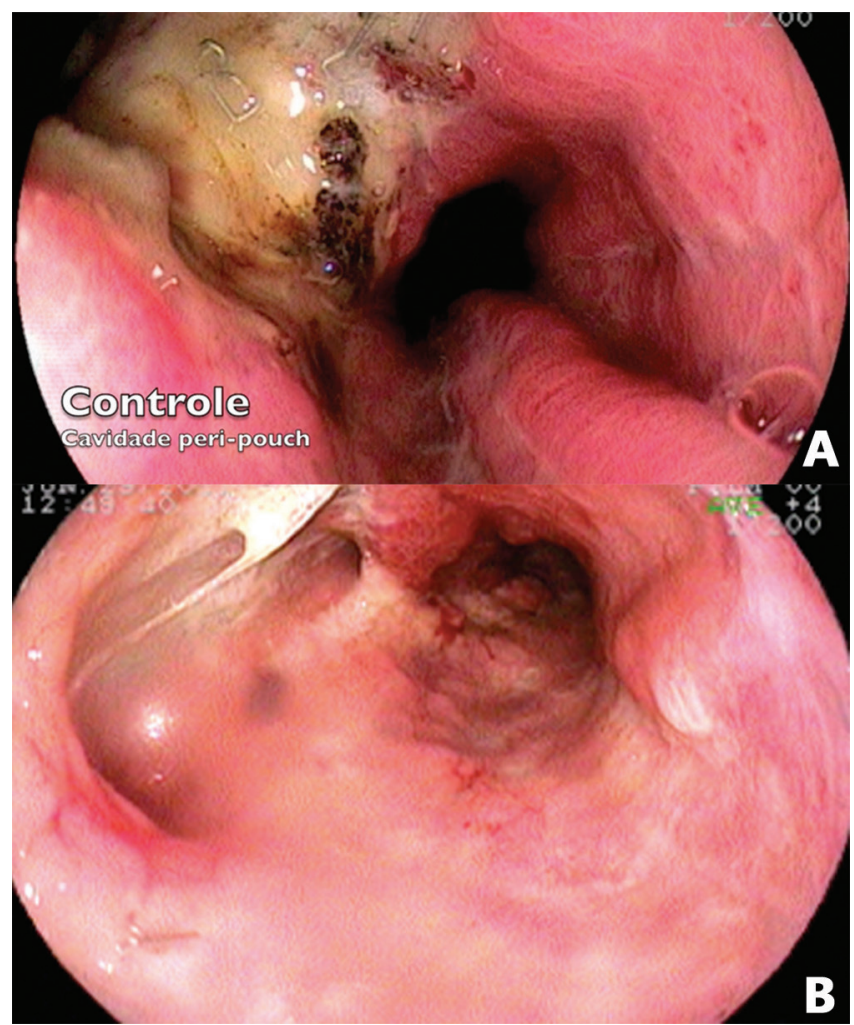

FIGURE 3 - Evolution of the healing process: A) initial appearance after septotomy with complete opening; B) final appearance in endoscopic control on day 30 post-septotomy

Endoscopic control was done after five days for completion of septoplasty with argon, observation of the incisura angularis and if the gastric pouch axis was already rectified. The fistula stopped draining to the skin on the $7^{\text {th }}$ day after the start of endoscopic treatment. The pre-endoscopic cavity formed by the fistula had its full resolution at 30 days (Figure 3), although the patient already carry out her activities and feeding with no problems.

\section{DISCUSSION}

Currently the author has treated 10 such cases with complete resolution in all no later than 60 days after the start of endoscopic treatment.

The proposed combination - dilation and septotomy with argon - unlike other services of bariatric endoscopy over the country, allows earlier resolution of post-sleeve gastrectomy fistulas, thus reducing the length of hospital stay, the need for enteral nutritional support or prolonged parenteral nutrition, as well as the need for reoperation and the risk of unfavorable outcome. The author do not makes the opening of the fistula before the $30^{\text {th }}$ postoperative day, because before this time there is the possibility of inexistence of healing blockage of the fistula area and the risk of penetration into free abdominal cavity with endoscopic devices. Generally with the more "forced" dilations mucosal laceration may occurs, but with only minor bleeding, not requiring hemostasis.

REFERENCES

1. Campos JM, Pereira EF, Evangelista LF et al. Gastrobronchial fistula after sleeve gastrectomy and gastric bypass: endoscopic management and prevention. Obes Surg. 2011: 21(10):1520-9.

2. Maluf-Filho F, Lima MS, Hondo $F$ et al. Experiência inicial no tratamento endoscópico de fístulas gastrocutâneas pósgastroplastia vertical redutora através da aplicação de matriz acelular fibrogênica. Arq Gastroentol. 2008; 45(3):208-11.

3. Thaler K. Treatment of leaks and other bariatric complications with endoluminal stents. J Gastroint Surg. 2009; 13:1567-69.

4. Yurcisin BM, DeMaria EJ. Management of leak in the bariatric gastric bypass patient: reoperate, drain and feed distally. J Gast Surg. 2009; 13:1564-66.

\section{ABCDDV/1067}

ABCD Arq Bras Cir Dig

Carta ao Editor

2014;27(3):81-83

\section{BARIATRIC SURGERY (SLEEVE GASTRECTOMY) AFTER LIVER TRANSPLANTATION: CASE REPORT}

\section{Cirurgia bariátrica (gastrectomia vertical) após transplante hepático: relato de caso}

Denis PAJECKI, Danielle Menezes CESCONETTO, Rodrigo MACACARI, Henrique JOAQUIM, Wellington

ANDRAUS, Roberto de CLEVA, Marco Aurelio SANTO, Luiz Augusto Carneiro D' ALBUQUERQUE, Ivan CECCONELLO

From the Serviço de Cirurgia Bariátrica e Metabólica, Disciplina de Cirurgia do Aparelho Digestivo e Disciplina de Transplante de Fígado do Hospital das Clínicas, Faculdade de Medicina, Universidade de São Paulo (Service of Metabolic and Bariatric Surgery, Department of Digestive Surgery and Department of Liver Transplantation, Hospital das Clinicas, Faculty of Medicine, Universidty of São Paulo), São Paulo, SP, Brazil.

Financial source: none Conflicts of interest: none

Correspondência:

Denis Pajecki

pajecki@netpoint.com.br
Received for publication: 12/03/2013 Accepted for publication: 24/07/2014

\section{INTRODUCTION}

$\mathrm{O}$ besity is a major public health problem worldwide; a quarter of the world's population is in the range of overweight and $10 \%$ are considered obese. In Brazil, half the population is overweight $\left(B M I>25 \mathrm{~kg} / \mathrm{m}^{2}\right)$ and $17.5 \%$ is obese $\left(\mathrm{BMI}>30 \mathrm{~kg} / \mathrm{m}^{2}\right)^{1}$. Bariatric surgery is the most effective method of treatment of severe or morbid obesity (BMI $>40 \mathrm{~kg} / \mathrm{m}^{2}$ or BMI>35 $\mathrm{kg} / \mathrm{m}^{2}$ with comorbidities), presenting superior results with respect to weight loss, control of comorbidities, improved quality of life and survival compared to medical treatment ${ }^{2}$.

Hepatobiliary complex interventions in severely obese patients are associated with increased risk of bleeding, postoperative complications and mortality, due to the technical difficulty (exposure) and higher incidence of clinical comorbidities ${ }^{3}$. 
Morbid obesity is a relative contraindication to liver transplantation for the same reasons. Furthermore, longterm survival of transplanted obese patients is also reduced. Nevertheless, in the United States, 7\% of patients undergoing liver transplantation are obese $e^{4}$. Some centers determine BMI less than 35 as a precondition for liver transplantation ${ }^{5}$. Furthermore, up to one third of patients undergoing liver transplantation become obese within three years postoperatively. The factors associated to this phenomenon are: sedentary lifestyle, improvement of appetite, change in eating habits (abandonment of the pre-transplant rigid diet), history of obesity and use of immunosuppressant, particularly corticosteroids ${ }^{6}$. Part of these individuals may become morbidly obese, and in some cases the development of steatosis in the transplanted liver, may even compromise the function of the graft. In this situation there is also an increase in the incidence of other comorbidities, such as type II diabetes. Patient education and dietary treatment are the key measures of prevention and treatment of obesity after liver transplantation ${ }^{7}$. In some situations, bariatric surgery may be indicated in order to delay or inhibit this evolution. There are few studies on the surgical treatment of morbid obesity after liver transplantation, all made in small series $8,9,10$.

Here is reported the case of one patient who underwent a laparoscopic sleeve gastrectomy 15 months after orthotopic liver transplantation, who developed stenosis of the biliary anastomosis and weight gain postoperatively.

\section{CASE REPORT}

Female of 33 years old with a history of obesity since childhood, was submitted in December 2012 to a liver transplant by piggyback technique, cadaver donor for autoimmune hepatitis and hepatitis C. The MELD score was 31 ; the patient had ascites and was admitted for treatment of spontaneous bacterial peritonitis and clinical compensation for two weeks prior to the transplant. In the day before the transplantation, she has shown little swelling, her weight was $106 \mathrm{~kg}$, height 1.69 $\mathrm{m}$ and BMI $37.1 \mathrm{~kg} / \mathrm{m}^{2}$. She received $10 \mathrm{U}$ of cryoprecipitate, 10 platelet apheresis and $650 \mathrm{ml}$ of autotransfusion through the cell saver. The early postoperative outcome was without any clinical or surgical complications. In the late postoperative period (after three months) she started to gain weight, reaching $134 \mathrm{~kg}$ after 10 months $\left(\mathrm{BMI}=47 \mathrm{~kg} / \mathrm{m}^{2}\right)$, associated with onset of hypertension and type II diabetes. She has received dietary counseling, managing to reach $112 \mathrm{~kg}\left(B M I=39 \mathrm{~kg} / \mathrm{m}^{2}\right)$ and stabilizing at that level, with partial improvement of diabetes and hypertension (still in need of medication for the treatment of both). Concomitantly, the patient developed stenosis of the biliary anastomosis, initially treated by percutaneous external drainage and later by combined internal and external drainage (rendezvous). For the definitive treatment of the biliary stenosis, a coledochal-jejunal anastomosis was proposed. Due to the degree of obesity presented by the patient, presence of comorbidities and risk of reoperation on the biliary tract in obese patients, bariatric surgery was proposed, so that the patient could have good weight loss, better control of comorbidities and better surgical conditions for the revisional procedure on the bile duct. After 15 months of transplantation, the patient underwent a laparoscopic sleeve gastrectomy. The operation began by lysis of adhesions and the separation of the left lobe of the liver, firmly attached to the anterior wall of the stomach (Figure 1). Stapling was started at $4.0 \mathrm{~cm}$ from the pylorus, and a $32 \mathrm{Fr}$ "bougie" was used for calibration. Was used green cartridge for the first staple line (Ethicon $\left.{ }^{\circledR}\right)$, gold for the second and blue in three subsequent shots (five in total, all $60 \mathrm{~mm}$ ). Oversuture of the staple line was held with Vicryl ${ }^{\circledR} 2.0$ line, a distance of about $5 \mathrm{~cm}$ from the esophagogastric angle, and thereafter continuous transfixing suture of the staple line (hemostatic) until the end of it (Figure 2). Was performed fixation of the omentum along the staple line with the objective of reducing adhesions and help prevent rotation of the stomach and drained the cavity with silicone tube. The surgical time was 120 minutes, anesthetic time of 150 minutes. There was no need for transfusions and the patient had a good postoperative course. The abdominal drain was removed on the $7^{\text {th }}$ day after radiological evidence of the absence of fistula. There was good food adaptation and resumption of oral immunosuppressive medication from the $2^{\text {nd }}$ postoperative day. The patient has lost $30 \mathrm{~kg}$ during the first 150 days post-operatively, which represented $75 \%$ of excess weight. There was good control of diabetes and hypertension, with discontinuation of medication for both. There was no change in liver function throughout evolution, so far. The definitive treatment of the biliary stenosis through biliary-digestive anastomosis is now being programmed.

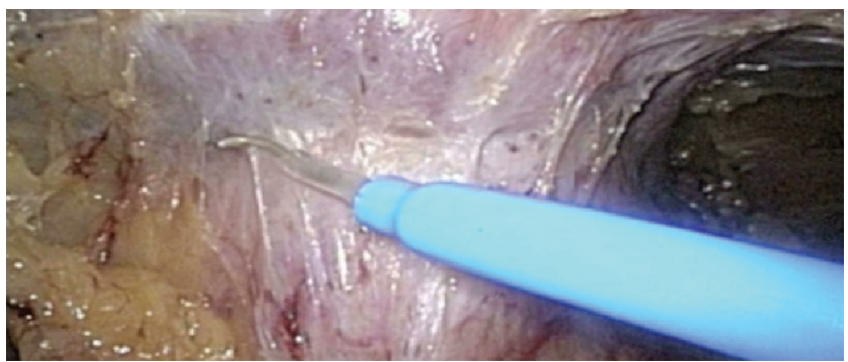

FIGURE 1 - Aspect of the adhesions of the left lobe of the liver to the anterior gastric wall

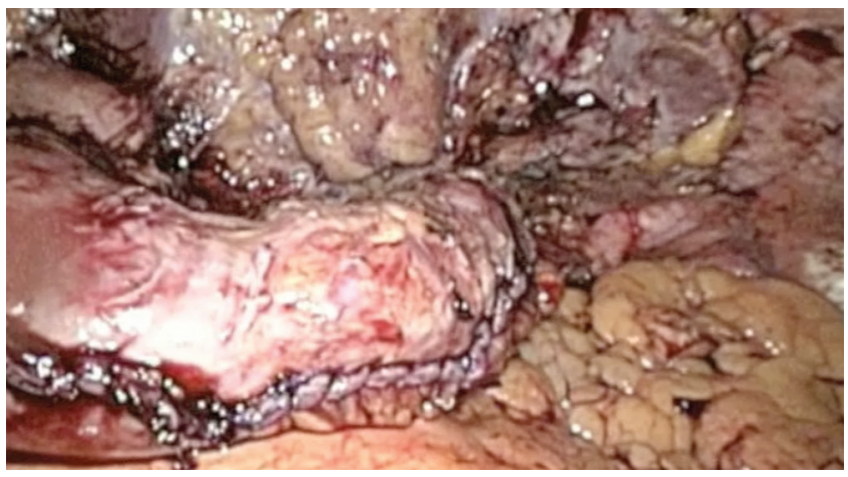

FIGURE 2 - Final aspect of the sleeve gastrectomy

\section{DISCUSSION}

In recent years, improvements in perioperative care has enabled an increase in survival of transplant patients, which reaches levels of 85 to $90 \%$ at one year and $70-80 \%$ after five years in high volume centers ${ }^{11}$. Nevertheless, the impact of obesity on long-term results of liver transplantation has become increasingly evident, associated with recurrence of $\mathrm{NASH}$ and increased incidence of diabetes, dyslipidemia and cardiovascular disease, jeopardizing the survival of these patients ${ }^{12}$. In this sense, although it is a big risk, treating obesity in these patients is warranted, including surgical procedures. For this reason, Heinbach et al. ${ }^{13}$ performed orthotopic liver transplants associated with sleeve gastrectomy in seven patients with $\mathrm{BMI}>35 \mathrm{~kg} / \mathrm{m}^{2}$. There was one fistula, with good evolution, and no mortality or graft loss in any case. No patient developed steatosis or type II diabetes in the late follow-up. In the other hand, in a group of 34 patients with similar characteristics, submitted to isolated transplantation, steatosis was observed in $12 / 34$, and type II diabetes has been diagnosed in $21 / 34$ patients ${ }^{13}$. Others have used the same technique in obese patients in a liver transplantation program, but prior to the transplant, with low morbidity and no mortality ${ }^{14,15}$. In the 
presented case, the patient was obese since childhood and unresponsive to dietary treatment. She was transplanted with a high BMI, but in a situation that would certainly not enable prior treatment for weight loss, given the complications (ascites, SBP) and high MELD.

Sariatric surgery after liver transplantation was first described by García Duchini and Brunson in 20018, who performed conventional gastric bypass in two patients, with good results (weight loss, normalization of blood glucose levels, regression of steatosis). The first case of laparoscopic gastric bypass was described by Tichanski and Madan in 2005, also with a good outcome ${ }^{15}$. However, a retrospective study conducted at the University of Minnesota, which evaluated seven patients who underwent conventional bypass after liver transplantation between 2001 and 20099, revealed that two patients died six and nine months after bariatric surgery of multiple organ failure and metastatic esophageal squamous cell carcinoma, respectively. Another patient had the operation reversed for severe malnutrition and four patients had good results (57\%).

More recently, Lin et al. ${ }^{10}$ performed sleeve gastrectomy in nine patients with a past of liver transplantation, eight by videolaparoscopy and one by laparotomy. The mean operative time was 165 min and the mean hospital stay was five days. One patient operated by videolaparoscopy developed a biliary fistula from the liver surface and required reoperation for drainage; and another had postoperative dysphagia which was also treated surgically. There was no mortality. Eli et al. ${ }^{16}$ performed the same procedure by robotics, with good results. In this case, the most laborious surgical time was certainly detachment of the left lobe of the liver adhered to the anterior wall of the stomach. Was carry out drainage routinely in patients undergoing sleeve gastrectomy because is believed that it can contribute to the early diagnosis of a fistula, avoid reoperation and it do not add morbidity to the procedure. The small number of studies and cases operated in the described situation, do not allow a conclusion or consensus as to the optimal bariatric technique after liver transplant. Roux-en-Y gastric bypass is associated with malabsorption of micronutrients (iron, calcium, zinc, copper) and vitamins (B12 and D) and can affect the absorption of immunosuppressive drugs, which could theoretically compromise the evolution of the patients ${ }^{17}$. The adjustable gastric band, which has also been used $^{18}$ is the insertion of a foreign body that can cause an increased risk of infection in immunocompromised patients. Sleeve gastrectomy has occupied the space of the adjustable gastric band, promotes greater weight loss, do not demand the maintenance required by the band and also does not compromise the absorption of either nutrients or medications ${ }^{19}$. For this reason, it has been the preferred technique by most authors for the treatment of morbid obesity in patients with liver disease before or after liver transplantation. However, more studies are needed to assess the progress and long-term complications in transplant patients undergoing bariatric surgery, as well as the best technique for treating this group of patients.

\section{REFERENCES}

1. Nair S, Cohen DB, Cohen MP et al. Post-operative morbidity, mortality, costs and long term survival in severely obese patients undergoing orthotopic liver transplantation.Am J Gastroenterol 2001;96(3): 842-5.

2. Weiss H, Nehoda H, Labeck B, Oberwalder M, Konigsrainer A, Margreiter R . Organ transplantation and obesity: evaluation, risks and benefits of therapeutic strategies . Obes Surg. 2000;10:465-469.

3. Akarsu M, Bakir Y, Karademir S et al. Prevalence and risk factors for obesity after liver transplantation: a single center experience. Hep Mont 2013;13(8):

4. Anastacio LR, Ferreira LG, Liboredo JC et al. Overweight, obesity and weigh gain up to three years after liver transplantation. Nutr Hosp 2012;27(4):1352-1356.

5. Leonard J, Heinbach JK, Malinchoc M et al. The impact of obesity on long-term outcomes in liver transplant recipients. Results of the NIDDK Liver transplant Database. Am J Transplant 2008;8:667-672.

6. Duchini A, Brunson ME. Roux-en-Y gastric bypass for recurrent nonalcoholic steatohepatitis in liver transplant recipients with morbid obesity. Transplantation. 2001 Jul 15;72(1):156-9.

7. Al-Nowaylati AR, Al-Haddad BJ, Dorman RB et al. Gastric bypass after liver transplantation. Liver Transpl. 2013 Dec;19(12):1324-9.

8. Lin MY, Tavakol MM, Sarin A et al. Safety and feasibility of sleeve gastrectomy in morbidly obese patients following liver transplantation. Surg Endosc. 2013 Jan;27(1):81-5

9. Heimbach JK, Watt KDS, Poterucha JJ et al. Combined liver transplantation and gastric sleeve resection for patients with medically complicated obesity and end-stage liver disease. Am J Transp. 2013;13:363-8.

10. Tichansky DS, Madan AK. Laparoscopic Roux-en-Y gastric bypass is safe and feasible after orthotopic liver transplantation. Obes Surg. 2005 Nov-Dec;15(10):1481-6. 